\title{
Distal spinal cord stimulation in infants with myelomeningoceles: preliminary study
}

\author{
A. Leland Albright, MD \\ Pediatric Neurosurgery, Department of Surgery, Kijabe Hospital, Kijabe, Kenya; and Department of Neurosurgery, University of \\ Wisconsin Health Center, Madison, Wisconsin
}

OBJECT The purpose of this study of infants with myelomeningoceles was to evaluate the effect of stimulation of the distal spinal cord, proximal to the neural placode, on functioning lower-extremity muscles distal to the placode.

METHODS In 13 infants with lumbosacral myelomeningoceles, the lateral spinal cord was stimulated, with a monopolar probe, between its exit from the spinal canal and the neural placode. Responses of functional muscles in the lower extremities were monitored with a neural integrity monitor.

RESULTS Stimulation of the lateral spinal cord resulted in no contraction of lower-extremity muscles in 7 of 13 infants in whom no nerves exited the cord between the spinal canal and the neural placode. In those with exiting nerves in that location, stimulation of the cord resulted in the contraction of functional muscles. Distal cordectomies at the junction between the spinal cord and the neural placode, distal to any nerve roots exiting from the cord, resulted in no loss of movement.

CONCLUSIONS Monopolar stimulation of the lateral spinal cord does not seem to cause contraction of functional lower-extremity muscles unless nerve roots to the lower extremities exit the cord distal to the spinal canal but before its junction with the neural placode. Muscle contraction in cases in which nerve roots exit the spinal cord between the canal and the placode may be caused by the spread of current from the monopolar stimulator.

http://www.thejns.org/doi/full/10.3171/2014.10.PEDS14202

KEY WORDS myelomeningocele; spinal cord stimulation; distal cordectomy; spine

$\mathrm{W}$ E recently reported on the treatment of lumbosacral myelomeningoceles with distal cordectomies. ${ }^{1}$ We reviewed the medical records of 32 infants (between 1 day and 7 months of age) with lumbosacral myelomeningoceles who had some voluntary lower-extremity function preoperatively and who were treated by distal cordectomies, which divided the spinal cord between its exit from the spinal canal and the neural placode. Neurological function was unchanged after the operation in 29 of 32 cases. In that publication, we stated that "what seems to be unknown is whether there is a connection of motor pathways within the spinal cord proximal to the placode and nerves exiting from the placode to innervate lower-extremity muscles." The present study was conducted to evaluate that question, with a hypothesis that there is no conduction of motor pathways from the distal spinal cord through the neural placode to lower-extremity muscles.

\section{Methods}

This study involved 13 infants with myelomeningoceles who had some voluntary lower-extremity function before undergoing surgery. Paired subdermal electrodes (8227410, Medtronic Xomed) were inserted subcutaneously over functional lower-extremity muscles, and subdermal ground electrodes were inserted into the inferior gluteal region. Those electrodes and the stimulating monopolar electrode (Prass 8225101 standard stimulator probe, Medtronic Xomed) were connected to a patient-interface box, which in turn was connected to a nerve integrity monitor (NIM-Neuro 3.0, Medtronic).

The operations were performed as described previously by incising the skin around the periphery of the myelomeningocele and dissecting subcutaneously to the dura and then circumferentially around it. ${ }^{1}$ The dura was exposed $1-1.5 \mathrm{~cm}$ cephalad to the site where it exited from the spi- 
nal canal, opened in the midline from that point distally to the placode, and then opened laterally around the placode toward each side for 2-3 cm, exposing the inferior aspect of the placode. That dissection exposed the distal spinal cord, any nerves exiting the cord after it exited the spinal canal, and nerves exiting from the bottom of the placode to the lower extremities (Fig. 1A).

Stimulation of the nerves exiting from the bottom of the placode to the lower extremities at $1 \mathrm{~mA}, 4 \mathrm{~Hz}$, resulted in consistent, strong muscle contractions in the lower extremities, including muscles with function and those without function. Under loupe magnification $(\times 4.5)$, any nerves exiting the spinal cord between the cord's exit from the spinal canal and the neural placode were dissected away from the cord with microinstruments, and then the lateral aspect of the cord, overlying the lateral corticospinal tracts, was stimulated with the monopolar stimulator probe, with the tip of the stimulator momentarily touching the cord (Fig. 1B). Stimulation varied from 1 to $5 \mathrm{~mA}$, and responses from the subdermal electrodes were recorded on the NIM-Neuro console. The neural placode itself was not stimulated. Figure $1 \mathrm{C}$ shows the retraction of the spinal cord after its transection from the inferior aspect of the placode.

This study was approved by the Kijabe Hospital Institutional Review Board.

\section{Results}

Stimulation of the lateral cord resulted in no movement of functional muscles in the lower extremities in 7 of 13 cases (Table 1). Contraction of lower-extremity muscles occurred only in cases in which nerve roots exited the cord distal to the cord's exit from the canal and its junction with the neural placode. Stimulation of the cord did not cause contraction of any preoperatively nonfunctional muscle.

All 13 cases were treated by distal cordectomies, 12 at the junction of the distal cord and the inferior surface of the placode. None of these 12 patients had any postoperative deterioration in neurological function. The cordec- tomy at the site where the cord exited from the canal resulted in a mild decrease in hamstring strength in 1 infant.

\section{Discussion}

This preliminary study provides some evidence that spinal cord stimulation proximal to the neural placode does not result in contraction of functional muscles distal to the placode. The observation that cord stimulation resulted in contraction of functional muscles in cases in which nerve roots exited the cord between the canal and the placode may represent spread of monopolar current from the stimulating site to those nerves.

The observation that monopolar stimulation of nerves exiting from the neural placode to the extremities resulted in strong muscle contractions at $1 \mathrm{~mA}$ is in keeping with the results of Pugh et al., ${ }^{2}$ who found easily excitable responses to bipolar stimulation of those nerves in distinct myotomal patterns in 2 neonates with myelomeningoceles.

The observation that cordectomies performed at the junction between the distal spinal cord and the neural placode resulted in no deterioration of neurological function in 12 of 12 cases provides additional support for the technique.

The effects of distal cordectomies on bladder and bowel function are unknown. For infants who have preoperative toe flexion, undergo distal cordectomies, and have the same motor function postoperatively, urodynamics are done within 1 week after the operation to determine whether intermittent catheterization is needed. Thus far, none of the few tested have needed it, but longer follow-up time is needed. It is plausible that distal cordectomies will diminish the development of hypertonic, "spastic" bladders. Infants without toe flexion are usually begun on intermittent bladder catheterization and asked to return 3 months later for urodynamics.

\section{Conclusions}

Monopolar stimulation of the lateral spinal cord does not seem to cause contraction of functional lower-extrem-
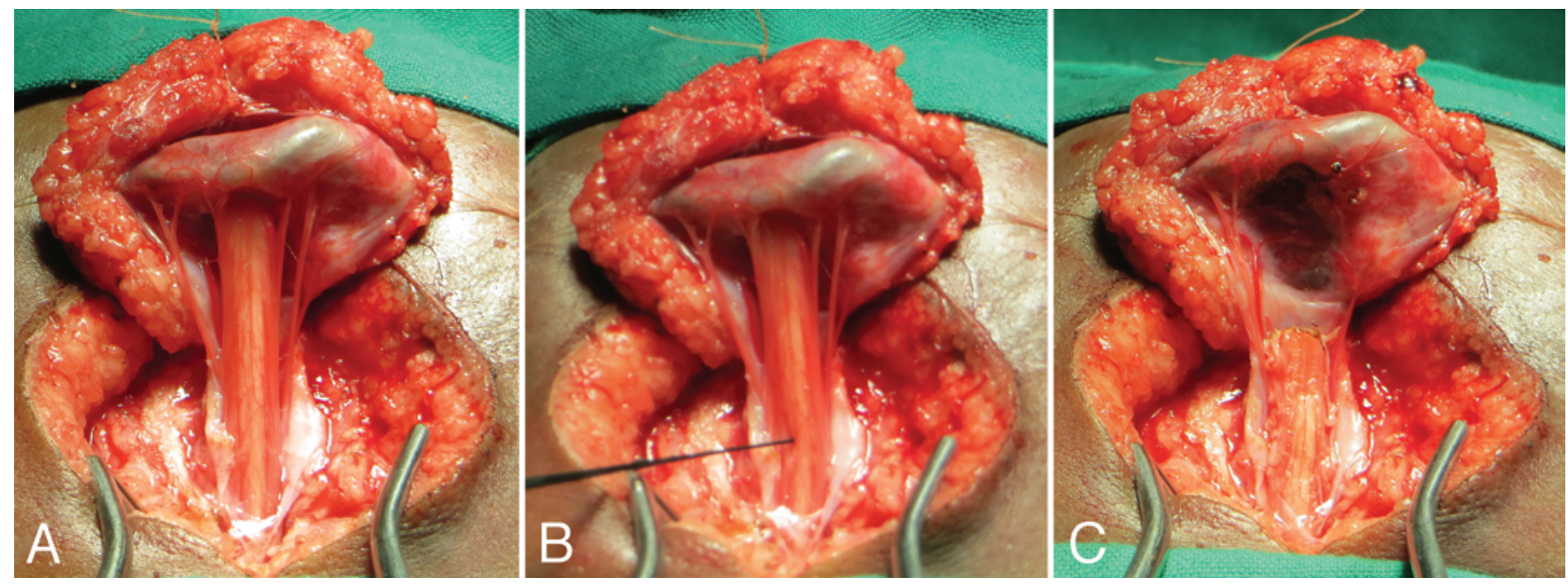

FIG. 1. A: Exposure of the distal cord and its junction with the inferior surface of the placode. B: Monopolar stimulation of the lateral cord. C: Proximal retraction of the cord after distal cordectomy. 


\section{A. L. Albright}

TABLE 1. Summary of spinal cord stimulation and muscle responses

\begin{tabular}{|c|c|c|c|c|c|c|c|c|}
\hline \multirow[b]{2}{*}{ Patient No. } & \multirow[b]{2}{*}{ Preop Function } & \multirow[b]{2}{*}{ Muscles Stimulated } & \multicolumn{2}{|c|}{ Cord Stimulation $(\mathrm{mA})$} & \multicolumn{2}{|c|}{ Stimulation Response } & \multirow[b]{2}{*}{$\mathrm{Rx}$} & \multirow[b]{2}{*}{ Postop Function } \\
\hline & & & Rt & $\mathrm{Lt}$ & Rt & $\mathrm{Lt}$ & & \\
\hline $1^{*}$ & Hip fl/ext, knee fl/ext & Quads, HS & 1 & $1-3$ & HS & None & 1 & Unchanged \\
\hline $2 \dagger$ & Hip fl/ext, knee fl/ext & Quads, HS & $1-3$ & $1-3$ & None & None & 2 & $\begin{array}{l}\text { Hip fl/ext same, } \\
\text { knee ext less }\end{array}$ \\
\hline 3 & Norm & HS, gastrocs & $1-3$ & $1-3$ & None & None & 1 & Norm \\
\hline 4 & Norm except no pf/toe fl & Quads, HS & $1-3$ & $1-3$ & None & None & 1 & Unchanged \\
\hline 5 & Norm & HS, gastrocs & 3 & 3 & HS & HS & 1 & Norm \\
\hline $6 \ddagger$ & Norm except no pf/toe fl & Quads, HS & 1 & 1 & Gluteals, HS & Gluteals, HS & 1 & Unchanged \\
\hline $7 \S$ & Norm except no pf/toe fl & HS, ant tib & $1-5$ & $1-5$ & $\begin{array}{l}\mathrm{HS} \text {, ant tib (only } \\
\text { at } 5 \mathrm{~mA} \text { ) }\end{array}$ & $\begin{array}{l}\mathrm{HS} \text {, ant tib (only } \\
\text { at } 5 \mathrm{~mA} \text { ) }\end{array}$ & 1 & Unchanged \\
\hline 8 & Norm except no pf/toe fl & Quads, HS & 1 & 1 & HS only & HS only & 1 & Unchanged \\
\hline 9 & lliopsoas, quads & Quads & 1 & 1 & None & None & 1 & Unchanged \\
\hline 10 & Quads, HS & Quads & 1 & 1 & None & None & 1 & Unchanged \\
\hline 11 & Norm & HS, gastrocs & 1 & 1 & None & None & 1 & Norm \\
\hline $12 \pi$ & Norm & HS, gastrocs & $1-3$ & $1-3$ & None & None & 1 & Unchanged \\
\hline 13 & Hip fl/ext, knee fl/ext & Quads, HS & 1 & 1 & None & None & 1 & Unchanged \\
\hline
\end{tabular}

ant tib = anterior tibialis; dist = distal; ext = extension; $\mathrm{fl}$ = flexion; gastrocs = gastrocnemius; $\mathrm{HS}$ = hamstrings; norm = normal; pf = plantar flexors; prox = proximal; quads = quadriceps; Rx 1 = cordectomy at the junction of the distal spinal cord and inferior surface of the neural placode; $\mathrm{Rx} 2=$ cordectomy at the level at which the cord exited the spinal canal.

* In Patient 1, the right hamstring muscles contracted in response to right cord stimulation at $1 \mathrm{~mA}$, but there was no response to left cord stimulation at 1-3 mA. † Patient 2, who had less knee extension postoperatively, had the cordectomy at the level at which the cord exited the spinal canal rather that at its junction with the placode.

‡ Patient 6 had 2-3 nerves exiting the spinal cord between its exit from the canal and its junction with the placode. Stimulation of the lateral cord between those nerves caused the same distal contractions as stimulation of the nerves themselves.

$\S$ In Patient 7, stimulation of the distal cord at $5 \mathrm{~mA}$, but not less, caused muscle contraction.

II In Patient 12, stimulation of the cord between exiting nerves just distal to the canal caused muscle contractions. Stimulation of the distal cord immediately proximal to the placode caused no contractions.

ity muscles unless nerve roots to the lower extremities exit the cord distal to the spinal canal but before its junction with the neural placode.

\section{Acknowledgment}

The donation of the nerve integrity monitor by Medtronic, Inc., is gratefully acknowledged.

\section{References}

1. Albright AL, Okechi H: Distal cordectomies as treatment for lumbosacral myelomeningoceles. J Neurosurg Pediatr 13:192-195, 2014

2. Pugh JA, Aronyk KE, Norton JA: Neural activity generated in the neural placode and nerve roots in the neonate with spina bifida. J Neurosurg Pediatr 9:452-456, 2012

\section{Correspondence}

A. Leland Albright, Kijabe Hospital, P.O. Box 20, Kijabe 00220, Kenya. email: 1.albright@neurosurgery.wisc.edu. 